\title{
Rascals, Triflers, and Pragmatists: Developing a Peircean Account of Assertion ${ }^{1}$
}

\author{
Kenneth Boyd and Diana Heney
}

The topic of assertion has recently received a fresh wave of interest from Peirce scholars. Approaches have ranged from showcasing Peirce's responses to particular problematic assertions to investigating the possible power of a Peircean commitment view of assertion in the scheme of the contemporary landscape (Atkins 2011, Heney 2015, Boyd 2016). These newer efforts add to the insights of the important papers of the past, including Brock (1981), Martens (1981), and Hilpinen (1982). However, to this point, no systematic account of Peirce's view of assertion has been attempted. We think that this is a lacuna that ought to be filled. Doing so will help make better sense of Peirce's pragmatism; further, what is hidden amongst various fragments is a robust pragmatist theory of assertion with unique characteristics that may have significant contemporary value. Here we aim to uncover this theory, and to show that assertion for Peirce is not a mere corollary of pragmatic conceptions of truth, judgment, and belief, but is rather a central aspect of his philosophy.

One good reason why it is difficult to give a systematic account of assertion for Peirce is that it is a topic that Peirce himself treated in an unsystematic way. We have thus set ourselves two tasks. The first is to bring to order Peirce's often scattered and incomplete thoughts about assertion. As we argue in section I, Peirce's remarks about assertion span a significant amount of his career, so it is worthwhile to get a sense of their order and development. Our second and most

\footnotetext{
${ }^{1}$ The authors, listed here in alphabetical order, are jointly responsible for all assertions in this paper. We thank our audiences at the SSHAP Symposium at the 2015 Central Division APA and the meeting of the Charles S. Peirce Society at the 2016 Eastern Division APA for excellent discussions on various proto-versions of this paper. Thanks also to Richard Atkins and Andrew Howat, our frequent interlocutors on the main topics of this paper, and two anonymous referees for their thoughtful comments.
} 
significant task is to flesh out a robust Peircean view of assertion. We do so in sections II

through IV by showing that Peirce regards assertion as importantly connected to truth, reality, and responsibility, and in interesting and unique ways.

\section{Assertion in Peirce's Writings}

Peirce's philosophical interest in assertion unfolded alongside the Fregean set-up for the linguistic turn and the subsequent $20^{\text {th }}$ century flowering of speech act theory. This means that Peirce scholars have an interesting job to do in the context of the history of philosophy, which is to elucidate his views on assertion so that we might see how much they forecasted or positively impacted later developments. As concerns us more immediately in this paper, Peirce scholars have the different, but equally interesting, job of ascertaining whether or not Peirce truly had a theory of assertion at all, rather than a series of disconnected insights.

To demonstrate that he had a theory of assertion requires attending not just to what he wrote, but also when he wrote it, and in what context. ${ }^{2}$ Despite the seemingly scattered nature of his remarks on this topic, Peirce argues for his view of assertion in terms that are consistent, and consistently intertwined, with other longstanding elements of his philosophy. Here, we bring forward his most explicit treatments of the topic.

\footnotetext{
${ }^{2}$ As Nathan Houser has emphasized, "Peirce's philosophy does not consist of a set of static doctrines, thought up and written down for once and for all; its development over his more than fifty years of scholarship appropriately represents his Darwinian motivation" (1992: xxiii). Gérard Deledalle also argues that Peirce's "writings must be studied chronologically if they are not to appear incomprehensible or contradictory" (1990: xxxi).
} 
Let us turn to the texts. A search of the Collected Papers alone turns up, by our count, 141 non-trivial hits for the term 'assertion'. ${ }^{3,4}$ We can first consider the broad parameters. Peirce recorded thoughts about assertion at least as early as 1869 (W2: 262-3) ${ }^{5}$, and at least as late as 1908 (CP 5.546, R 297). ${ }^{6}$ In the intervening four decades, he returned to the topic on many occasions: assertion, like other essential strands of Peirce's system, is an enduring interest. ${ }^{7}$ It will become clear that the endurance of Peirce's interest makes sense given the ways in which assertion is tangled up with those other essential strands - it is nigh impossible to pull on the strands concerning truth, reality, responsibility, or science without thereby also pulling assertion into the picture.

Although Peirce discusses assertion throughout his philosophical career, his most substantial treatment of assertion comes after 1895, and thus we will be focussing predominantly

\footnotetext{
${ }^{3}$ Heney has produced a catalogue of these references. It is an incomplete record of Peirce's interest - the full story requires similar surveys of the chronological Writings and the manuscripts themselves, as well as a parallel search for 'proposition' (at times used interchangeably by Peirce, especially in his early writings) - but a compelling beginning. Despite its imperfections, the Collected Papers remains a standard source. The reader may also wish to consult the Robin catalogue, which lists the following manuscripts as centrally concerned with assertion: R 284 . $297 ; 334 ; 517 ; 636 ; 664 ; 744 ; 792 ; 804-5 ; 1408$. As with the $C P$, a full survey requires investigation of 'proposition' and 'judgment'.

${ }^{4}$ This number does not include those references occurring in instances of 'sheet of assertion'. The phrase 'sheet of assertion' is most often not connected to any substantive discussion of the nature of assertion itself. For accounts of the existential graphs mapped from such sheets, see Don D. Roberts, The Existential Graphs of Charles S. Peirce and Sun-Joo Shin, The Iconic Logic of Peirce's Graphs.

${ }^{5} \mathrm{CP} 2.467$ (1867) could count as an earlier substantive reference because Peirce later modified it, altering 'proposition' to 'assertion', and in 1893 adding the note, 'Any assertion means merely how we would act under given circumstances ...' (MS 592).

${ }^{6}$ At least one reference suggesting continued philosophical engagement that is later yet is found in Peirce's correspondence, in a 1913 letter to F.A Woods where Peirce takes up the question of general assertions in connection with his own conception of truth (CP 8.380).

7 This metaphor is adopted from Douglas Anderson's Strands of System: The Philosophy of Charles Peirce. Rather than thinking of Peirce's thought as essential bifurcated and its parts irresolvable - as Thomas A. Goudge does in his influential The Thought of C.S. Peirce - exemplifying assertion as a deeply entangled strand that grows thicker through time respects the evolutionary character of Peirce's thought without requiring us to abandon some large part of it.
} 
on key texts from 1895 onwards $^{8}$. We begin with the first of three planks in our historical platform: $\S 5$ of the 1895 “That Categorical and Hypothetical Propositions are one in essence, with some connected matters", titled "The Nature of Assertion". The section starts directly: "Let us now consider in what the essential nature of assertion consists" (CP 2.332). What Peirce is offering here is advertised as an improved version of his own view on grammatica speculativa from "On a New List of Categories", which will now "leave little to be desired". Peirce begins with the methodological claim that an analysis of assertion requires two kinds of reasoning. "On the one hand, we can directly observe what is familiar to our experiences and seems to be inseparable from them". Such "rhetorical evidence", while "somewhat dark and formally imperfect" often goes "the deepest" (CP 2.333). In addition to the consideration of rhetorical evidence - what we might now regard as the purview of ordinary language philosophy - Peirce adds a second mode of reasoning, which "consists in deducing what the constituents of assertion must be from the theory, which I accept, that truth consists in the definitive compulsion of the investigating intelligence".

This is a classically Peircean approach to a concept of interest. After achieving the first grade of clarity - which would be exhibited by being able to grasp instances of assertion reliably, though inarticulately - the analytic project of definition offers the second grade of clarity. But the third, pragmatic grade of clarity requires the consideration of rhetorical evidence, that is, of how assertion plays its role in our everyday discursive practices. Further, neither mode of reasoning supersedes the others in the analysis of assertion; rather, "deductions ... from theory having been made, it is requisite to turn to the rhetorical evidence and see whether or not they are verified by

\footnotetext{
${ }^{8}$ One likely cause for the explicit interest in assertion late in Peirce's writings is that he returns to writing on assertion anew as he is reworking aspects of his semiotic. As Tom Short has convincingly argued, the development of Peirce's semiotic “was not completed until 1907” (Short 2007: 27).
} 
observation" (CP 2.333). This echoes Peirce's remarks on truth, which he thought demanded a similarly symmetrical development of theory: “[M]y three grades of clearness are not...such that either the first or the second are superseded by the third...I continue to admit that the third grade is the most important of all...But there is no reason why all three should not be symmetrically developed" (CP 8.218). It is unsurprising, then, though striking, that Peirce declares here that as "the analysis of assertion gain[s] evidence of being completely rounded", "the theory of truth is rendered more probable" (CP 2.333).

Let us collect Peirce's pieces of rhetorical evidence in this 1895 version. First, "In every assertion we may distinguish a speaker and a listener", though they may be one and the same person, or two persons who stand in a diachronic relation not evident in the moment of the initial utterance, or even who stand only in such a relation conceptually - as when one sends a message in a bottle without knowing who, if anyone, ever, will read it (CP 2.334). ${ }^{9}$ Second, the assertion stands as "the furnishing of evidence by the speaker to the listener that the speaker believes something", that she is, in fact, compelled to so believe (CP 2.335). Third, assertion is characterized by the effort to share the compulsion to believe what is asserted with the listener, through "a kind of sign", "an Index", which "directs attention...[to] the subject of the assertion" (CP 2.336).

With the basic ingredients outlined in 1895 , we can learn more about why Peirce regards assertion as significant through his 1905 Monist article, "What Pragmatism Is". This article is best known as the place where Peirce bemoans the fate of 'pragmatism' and introduces the term

\footnotetext{
9 This may bring to mind Ludwig Wittgenstein's argument concerning the possibility of private language from Philosophical Investigations. At $\$ 243$, he describes a private language, but then immediately ( $\$ 244 \mathrm{ff})$ argues that such a language is impossible. There is perhaps more than passing resonance here with Peirce's claim that every assertion requires an audience. The likely link between Peirce and Wittgenstein would be Frank Ramsey. For an excavation of that link, see Misak (2016).
} 
'pragmaticism' in print. It also highlights the importance of assertion for pragmaticism, as it is the first topic of the paper. Peirce offers his own experience of what he describes as the laboratory mindset. Those who share that mindset - experimentalists - have a "disposition ... to think of everything just as everything is thought of in the laboratory; that is, as a question of experimentation" (CP 5.411; 1905: 161). The mark of a true experimentalist, Peirce goes on to say, is not that he is "the typical doctor" or "the typical pedagogue", but that "whatever assertion you make to him, he will either understand as meaning that if a given prescription for an experiment ever can be and ever is carried out in act, an experience of a given description will result, or else he will see no sense at all in what you say" (CP 5.411; 1905: 162).

What we find here is that in Peirce's introduction of pragmaticism, of what he takes to be distinctive in his philosophy and absent from the pragmatisms of those to whom he has ceded the name, the pragmaticist is presented as someone who has a particular view of how assertion functions. The term 'pragmaticism' has, as Peirce predicted, proved "ugly enough to be safe from kidnappers" (CP 5.415; 1905: 166). Why his view of assertion has not been adopted is not so clear. Indeed, relatively little attention has been paid to the prominent presence of assertion at the scene of pragmaticism's public introduction. ${ }^{10}$ Though Peirce's treatment of assertion may seem unsystematic, those texts that do engage assertion directly are consistent with one another.

As evidence that this is so, consider a third explicit piece of text, a fragment from 1908. Though not embedded in an argumentative project of clear scope in the manner of the 1895 and 1905 offerings, this rich quotation brings together much of what came before and goes some way toward "rounding" Peirce's view of assertion in its relation to his conception of truth:

\footnotetext{
${ }^{10}$ Many of the prominent "big books" in the secondary literature of Peirce studies either do not explicitly treat assertion at all, or treat it as orthogonal rather than as of primary interest. A notable exception is Christopher Hookway's 1985 Peirce.
} 
If a man desires to assert anything very solemnly, he takes such steps as will enable him to go before a magistrate or notary and take a binding oath to it. Taking an oath is ... not mere saying, but is doing ... it would be followed by very real effects, in case the substance of what is asserted should be proved untrue. This ingredient, the assuming of responsibility, which is so prominent in solemn assertion, must be present in every genuine assertion. For clearly, every assertion involves an effort to make the intended interpreter believe what is asserted, to which end a reason for believing it must be furnished. But if a lie would not endanger the esteem in which the utterer was held, nor otherwise be apt to entail such real effects as he would avoid, the interpreter would have no reason to believe the assertion. Nobody takes any positive stock in those conventional utterances, such as "I am perfectly delighted to see you," upon whose falsehood no punishment at all is visited. At this point, the reader should call to mind, or, if he does not know it, should make the observations requisite to convince himself, that even in solitary meditation every judgment is an effort to press home, upon the self of the immediate future and of the general future, some truth. It is a genuine assertion, just as the vernacular phrase represents it ... Consequently it must be equally true that here too there is contained an element of assuming responsibility, of "taking the consequences." (CP 5.546-547; R 297)

Together with the 1895 text, this passage brings Peirce's conception of assertion into clearer focus. For an utterance or judgment to count as a genuine instance of assertion, it must involve:

(i) the existence of a speaker and hearer (be they actual or merely possible);

(ii) the expression of a proposition; 
(iii) the compulsion to accept that proposition as true on the part of the speaker and the effort to share that compulsion with the hearer; and

(iv) as a consequence of (i)-(iii), the taking of responsibility for the truth of the proposition expressed.

The 1895/1908 texts complement each other, with the latter amplifying the importance of the element of taking responsibility. The intervening 1905 remarks help us to see why it matters: to understand assertion pragmatically, with the laboratory mindset, is at the very heart of what Peirce's philosophy demands - and it is precisely to see assertion as demonstrating a commitment.

What we can conclude from our preliminary historical survey is that in Peirce's most explicit writings on assertion, one sees deep connections with other areas of his work, and none of the self-contradiction for which his philosophical thought is sometimes caricatured. We see a piece of the puzzle that has stayed more or less in place as the system evolved, becoming only more prominent in importance. Indeed, the philosophical takeaway thus far is that the three texts considered reveal in a striking way the pragmatic entanglements of Peirce's view of assertion. The first entanglement pertains to the notion of truth: the speaker not only presents the proposition asserted as a candidate for belief, but is making "an effort" to persuade the other to accept it as true. Second, the notion of reality: any assertion that turns out to be false has, as an upshot of its falsity, "real effects" on the one who asserts it. Third, the notion of responsibility: it is in experiencing those real effects that we "take the consequences", and every genuine assertion involves "the assuming of responsibility". We now move on to unpacking the ways in which Peirce's philosophical commitments concerning assertion are tied up with these notions. 


\section{Pragmatic Entanglements: Truth}

Peirce scholars have devoted considerable effort to developing and defending his view of truth, especially as it compares with other accounts that have been offered by pragmatists or neopragmatists. In Susan Haack's Evidence and Inquiry, she defends Peirce's insistence on the importance of truth against Richard Rorty's eliminative approach. ${ }^{11}$ Haack gives a nutshell of Peirce's conception of truth "as the hypothetical ideal theory", such that the truth is "the 'ultimate opinion' that would survive all experiential evidence and full logical scrutiny" (1993: 189). In Truth and the End of Inquiry, Cheryl Misak is careful to clarify that the 'ultimate opinion' does belong in scare quotes, for Peirce is not "claiming that a necessary condition of a hypothesis being true is that it will be believed at the end of inquiry" (2004 [1991]: 67-8). Misak sees Peirce as holding that "the fact that the final opinion may never materialize does not alter the truth-value of conditionals asserting that if the final opinion were to materialize, then the [true belief] would be in it" (2004 [1991]: 69).

What matters most for our purposes here is that Peirce adopts truth as a regulative ideal of inquiry - that is, he argues that inquiry itself is characterized by aiming at the truth. This means that any proposition asserted as the outcome of a process of inquiry will be one which we can hold up to the epistemic standard appropriate to inquiry itself. Assertions are precisely the kind of thing for which we should ask, "but is it true?"

We turn now to more specific ways in which truth plays a role in understanding Peirce's account of assertion: as it is elucidated in connection with the nature of propositions, as it is

\footnotetext{
${ }^{11}$ What Rorty is most concerned to eliminate is any reference to reality, which could suggest a lingering representationalist ideal. Huw Price does an excellent job of describing Rorty's avoidance of the representational and Rorty's reasons for rejecting Peirce's account of truth - in his (2003). However, Peirce's insistence on reality in no way renders him a representationalist (see Heney 2015).
} 
developed in what Peirce calls the "third grade" of clarity, and as it stands as the norm of assertion.

\section{Truth and the nature of propositions}

The first pragmatic entanglement that we will explore is that between assertion and truth. Although there is a superficial relationship between the concepts - as propositions are bearers of truth values, and assertions are acts that express propositions - looking more closely at the nature of propositions reveals a more important connection between them. What, then, is a proposition for Peirce? Peirce's final view comes after the turn of the century, when he defines a proposition as "a sign which separately indicates its object" (CP 2.357; L 34). In terms of his semiotic, Peirce classifies propositions as Dicisigns, which, as Frederik Stjernfelt (2015) puts it, are signs "which say something about something" $(1021)^{12}$. As a result, Peirce is liberal with the kinds of things that can qualify as propositions: not merely units of language and thought, but gestures, weathervanes, maps, and diagrams can all be propositions, as well. What unifies all of these disparate things is that they convey information and that they can be evaluated as true or false, although they do not provide any reasons for their truth or falsity (hence distinguishing propositions from arguments). Finally, propositions share a common structure, requiring both an index and an icon.

The notion of assertion plays a key role in Peirce's development and elucidation of the concept of the proposition. For instance, at times Peirce equates a proposition with a potential assertion, as when he states that "a proposition is always understood as something that might be assented to and asserted" (CP 2.315; R 478), as well as when he says that a "proposition is a sign

\footnotetext{
${ }^{12}$ For a more thorough treatment of Peirce's theory of Dicisigns, see Stjernfelt (2014).
} 
which is capable of being asserted" (CP 2.252). That a proposition is something that can be potentially asserted demonstrates an important connection between propositions and assertion. First, note that propositions for Peirce are not merely combinations of logical syntax: in order to be meaningful, propositions have to say or represent something. Consider, for instance, a remark made by Peirce in 1873:

The logical term or name is a maimed and imperfect representation because it says nothing. It requires something added to it in order to make it refer to any particular object as an assertion that that object has such a name applicable to it... (R 212)

Since mere logical terms or names on their own do not represent anything, an important part of making sense of a proposition is to figure out how they can come together to represent something in the form of a proposition. Peirce will sometimes refer to this missing piece of the puzzle as what the proposition itself asserts.

The kind of asserting that a proposition does is clearly different from the kind of asserting that a person does in the form of a speech act. But there are two important connections between these kinds of assertions: first, the way that Peirce develops his notion of a proposition affects how he conceives of the speech act of assertion. Second, there is potentially an interesting historical reason why Peirce developed his notion of the speech act of assertion at the time that he did, namely that in attempting to discover how it is that a proposition asserts its own truth he was led to think more about the nature of the speech act of assertion. Consider, for instance, part of his correspondence with Christine Ladd-Franklin: in her 1889 article "On Some Characteristics of Symbolic Logic", Ladd-Franklin states that "common logic has long since forced all propositions into the mould, -subject, copula, predicate" (552). In a letter, Peirce takes exception to Ladd-Franklin's definition: 
I should think, on the contrary, that if any such conclusion followed, two members were required beside subject and predicate, one to express the nature of the relation, and the other to asseverate it. But what does this asseveration consist in? Would not an asseveration be a proposition without anything outside of it? It seems to be the very first duty of logician is to analyze asseveration and explain what it is. (L 237)

Peirce seems to be drawing Ladd-Franklin's attention to the problem he addresses in the passage from 1873 above: a mere string of subject, copula, and predicate do not themselves represent anything if we take these components to be merely logical terms or symbols. Peirce's focus on the analysis of the asseveration of a proposition may then have drawn his attention to how assertion works as a speech act.

Peirce's solution to the problem involves thinking differently about the nature of subjects and predicates themselves. Although the proposition can be described as an indication of a state of things or a potential assertion, the structure of a proposition remains the same:

A proposition consists of two parts, the predicate which excites something like an image or dream in the mind of the interpreter, and the subject, or subjects, each of which serves to identify something which the predicate represents. ( $\mathrm{R} 280$ )

The subject of a proposition is or represents "an indexical symbol" which directs the “interpreter's attention to a certain object or objects" (Hilpinen (1982): 183), where an indexical symbol, in turn, is a kind of sign which "denotes a thing by forcing it upon the attention" (CP 3.434; R 518). In terms of the images elicited by predicates, Peirce says the following: Not only is the outward significant word or mark a sign, but the image which it is expected to excite in the mind of the received will likewise be a sign - a sign by 
resemblance, or, as we say, an icon - of the similar image in the mind of the deliverer, and through that also a sign of the real quality of the thing. (CP 3.433; R 518)

The nature of a proposition as involving an icon is especially important when making sense of the relationship between propositions and assertions, as Peirce argues that "every assertion must contain an icon or set of icons, or else must contain signs whose meaning is only explicable by icons" (CP 2.278; MS 786). This is because an index cannot, by itself, convey any information: conveying information requires more than just getting one's attention, it's necessary to draw one's attention towards something, and only then can the index be "completed" with an icon in order to form a proposition (indeed, Peirce, will sometimes talk about the index as a kind of "incomplete" proposition (EP2: 307)). We can see, then, why so many different kinds of things can qualify as propositions for Peirce: gestures, weathervanes, maps, and diagrams all draw our attention towards some object and say something about it, which we can then evaluate as true or false. The nature of the proposition as requiring both an index and icon explains what happens when we assert a proposition: essentially, by asserting a proposition we try to get the members of our audience, whomever they should be (or would potentially be) to associate an icon with an index. The very nature of assertion, then, connects it to a pragmatic conception of truth in two ways: first, assertion is that act which exemplifies a commitment to the truth, and second, assertion is normatively constrained by the truth. We now address these points in turn.

\section{Truth in the third grade of clarity}

When Peirce says that assertion involves taking responsibility for the truth of a proposition, this should immediately bring to mind the pragmatic maxim: 
Consider what effects, that might conceivably have practical bearings, we conceive the object of our conception to have. Then, our conception of these effects is the whole of our conception of the object. (CP 5.402; R 290)

At the heart of pragmatism in general, we find this idea that our ownership and articulation of concepts cannot float free of our use of them in practice. Grasping a concept means not just recognizing and precisely defining it, but understanding its use in practical terms. We have seen Peirce emphasize that when we consider assertion, we find that we must talk of truth. As Huw Price has put the point, "in order to account for a core part of ordinary conversational practice, we must allow that speakers take themselves and their fellows to be governed by a norm stronger than that of justification" (2003: 168). Price's argument is that in assertion, our behaviour reveals that we take ourselves to be governed by a truth-norm. When we focus on the practice of assertion, truth is also always implicated.

But it is also the case that when truth is the concept in the crosshairs, we must talk of assertion. For just as Peirce casts truth as a regulative assumption of all inquiry, so, too reality and it is reality in the form of "external permanency" to which we take ourselves to be responding when we offer up a proposition in the mode of assertion, rather than hypothesis, speculation, or opinion (CP 5.384; R 407). Just as regulative assumptions concerning truth and reality express "habit[s] of mind which [govern]...inference" (CP 5.357; R 593), assertion expresses a habit of action which reveals commitment to the truth of a proposition, rather than some weaker attitude.

There is no lurking circularity here, for what is offered is not a definition of assertion in terms of truth and truth in terms of assertion. Rather, there is a pragmatic entanglement between 
the two concepts: when we apply the pragmatic maxim to the concept of truth, we see that one of the real effects of taking a proposition as true is that we express it as an assertion.

\section{Truth as the norm of assertion, both public and private}

That truth is the norm of assertion for Peirce is exemplified by the effects that one's assertion has. As we have seen, when one asserts, one attempts to get one's audience to accept the truth of some proposition. By asserting a proposition, one is making a particular claim about the state of things; one's assertion then fails in some way if the proposition asserted is false. There are other ways in which one's assertion can "fail", as well: one way pertains to those cases in which one performs a speech act that fails to qualify as an assertion. ${ }^{13}$ Another way pertains to those cases in which one's assertion fails some normative standard: when one asserts, one ought to assert that which is true.

For Peirce, however, assertion is not something that is solely an expression between a speaker and an external audience. Indeed, he argues that there is an important connection between assertion and judgment. For instance, in "The Meaning of 'Practical' Consequences" Peirce asks:

Do we not all perceive that judgment is something closely allied to assertion? That is the view that ordinary speech entertains. A man or woman will be heard to use the phrase, "I says to myself." That is, judgment is held to be either no more than an assertion to oneself or at any rate something very like that. (CP 5.29; R 301, emphasis original) The nature of judgments as "assertions to oneself" allows us to make sense of the normative standards for judgments:

\footnotetext{
${ }^{13} \mathrm{We}$ will see instances of this kind of failing below in the discussion of responsibility.
} 
At this point, the reader should call to mind...that even in solitary meditation every judgment is an effort to press home, upon the self of the immediate future and of the general future, some truth. (CP 5.546; R 297)

Judgments, then, can fail in the same way that assertions can, namely in terms of falling short of some normative standard. Like assertions, they succeed or fail according to the shared standard of truth. This shared normative standard is explained by Peirce's view that judgments just are assertions, namely assertions to oneself.

Peirce is not alone in positing an intimate connection between judgment and assertion. However, the relationship between these two concepts typically gives priority to judgments. Consider, for instance, Frege's take on the relationship. As Thomas Ricketts argues, Frege conceives of an assertion as "a manifestation of a judgment" which lends "a certain priority to the latter notion" (1986: 71). For Peirce, however, if there is any priority between the concepts it is the other way around: since judgments just are assertions, we need to get a handle on assertions first before we make sense of judgments.

While Peirce certainly seems correct in saying that "ordinary speech" often indicates that we at least talk about judgments as if we are talking to ourselves, it may seem implausible to claim that all judgments are simply assertions to oneself. After all, while all instances of assertions involve propositions, it's not clear whether all of our judgments are propositional in nature. Nevertheless, Peirce is committed to the view that all judgments are internal assertions. Consider, for example, in his second "Lecture on Pragmatism", where Peirce discusses perceptual judgments:

The whole question is what the perceptual facts are, as given in direct perceptual judgments. By a perceptual judgment, I mean a judgment asserting in propositional form 
what a character of a percept directly present to the mind is. The percept of course is not itself a judgment, nor can a judgment in any degree resemble a percept. It is as unlike it as the printed letters in a book, where a Madonna of Murillo is described, are unlike the picture itself. (CP 5.54; R 302)

When we make perceptual judgments - judgments about the character of a percept - the percept itself is not a proposition, but instead a part of the world that we see; Peirce's example here is "I see an inkstand on the table: that is a percept" (EP2: 61). A judgment about the character of the percept, however, represents the percept in a propositional form. To make a perceptual judgment, then, is still to assert to oneself that "such-and-such has a particular character."

We have seen that the normative standard for assertions is grounded in their status as attempts to get someone to accept something as true. But what about when I assert something to myself? Is it not a bit odd to say that the normative standard for a judgment is based on getting ourselves to accept something as true? This is perhaps not as odd as it might initially sound. For when asserting, one's audience does not need to be a specific, physical person or group of persons that exists in the here and now. Again, consider what Peirce says about the “problematical" existence of one's audience:

In every assertion we may distinguish a speaker and a listener. The latter, it is true, need have only a problematical existence, as when during a shipwreck an account of the accident is sealed in a bottle and thrown upon the water. The problematical "listener" may be within the same person as the "speaker"; as when we mentally register a judgment, to be remembered later. If there be any act of judgment independent of any registry, and if it have any logical significance (which is disputable), we may say that in that case the listener becomes identical with the speaker. (CP 2.334, MS 786) 
Robinson Crusoe, then, is still capable of making assertions, as his audience consists in whoever might be reading his messages in a bottle - even if no one ever, in fact, ends up reading them. One can still make an assertion to oneself, then, because the commitments one makes are to someone, even though that someone might not be hic et nunc. Rather, they have a problematical existence: when making a judgment, one's future self will later remember it, and it is to them that we are held accountable. Just as Robinson Crusoe is subject to the standards of proper assertion despite the possibility that no one will ever read his messages, we are subject to the standards of proper assertion to ourselves even if we never think about the content of that assertion in the future, or if our future self doesn't exist; say, because we die suddenly.

One might, however, have the following concern: assertions are typically taken to be a kind of speech act, and to judge the truth of something is not itself a speech act, and perhaps not even an act at all. So if assertions are acts, but judgments are not, how can judgments be kinds of assertions? Peirce says the following:

A judgment is an act of consciousness in which we recognize a belief...Of what nature is that recognition? It may come very near action. The muscles may twitch and we may restrain ourselves only by considering that the proper occasion has not arisen. But in general, we virtually resolve upon a certain occasion to act as if certain imagined circumstances were perceived. This act which amounts to such a resolve, is a peculiar act of the will whereby we cause an image, or icon, to be associated, in a peculiarly strenuous way, with an object represented to us by an index. This act itself is represented in the proposition by a symbol, and the consciousness of it fulfills the function of a symbol in the judgment. Suppose, for example, I detect a person with whom I have to deal in an act of dishonesty. I have in my mind something like a "composite photograph" 
of all the persons that I have known and read of that have had that character, and at the instant I make the discovery concerning that person, who is distinguished from others for me by certain indications, upon that index at that moment down goes the stamp of RASCAL, to remain indefinitely. (CP 2.435; R 595)

The above passage comes from 1893, but Peirce later drops the qualification that judgments are "very near action", arguing in 1908 that judgment is not just "a purely representitious event, but also involves an act, an exertion of energy, and is liable to real consequences, or effects" (CP 5.547; R 297). Elsewhere, he argues that "[a] judgment is a mental act deliberately exercising a force, tending to determine in the mind of the agent a belief in the proposition" (R 517). So my mental labelling of my image of a dishonest person with a "RASCAL" stamp is an act of my consciousness. We could, then, interpret this judgment as an assertion to myself that "so-and-so is a rascal", since I am representing this as a truth to myself. Again, we can think of what happens if we were to assert the same proposition to someone else: we would attempt to convince them of the truth of the proposition that "so-and-so is a rascal" by getting them to associate an icon - in this case, one's notion of being a rascal - with an index - in this case, the proper name which "so-and-so" stands for.

When making an assertion to someone else the context in which we assert is also an important determinant of what we are taking responsibility for. A particularly important aspect of the context is the background knowledge that we share with our audience: to get someone to think of so-and-so as a rascal, for example, we need to share some information about who soand-so is and what it means to be a rascal. When making assertions to ourselves our background beliefs play a similar role in determining the content of those assertions: if, for instance, I believe that "rascal" is a term of endearment, then my judgment regarding so-and-so will be different 
than the one I would form if I were to believe that rascals were contemptible. Judgment, then, is a kind of act for Peirce, namely that act of associating indices with icons, so there is no conceptual boundary here in saying that judgments are kinds of assertions.

So far we have argued that Peirce's view of assertion is entangled with his account of truth as implicated in propositions and in judgments. Assertion is normatively constrained by the truth, and, symmetrically, to consider a proposition true is be compelled to assert it. Further, Peirce's conception of judgment cannot be understood without appealing to a notion of assertion, and Peirce is perhaps unique amongst his contemporaries in arguing that assertion takes a kind of priority over judgment. We turn next to our second pragmatic entanglement: reality.

\section{Pragmatic Entanglements: Reality}

Orienting oneself with respect to Peirce's account of reality is a complex task, as his views underwent major changes as his system evolved. ${ }^{14}$ In his excellent primer on Peirce, Cornelis de Waal demonstrates that "for Peirce, truth coincides with the final opinion the object of which is reality" (2001: 49). But what kind of things can be real?

Robert Lane (2004) has traced some of the key developments toward what Peirce referred to in 1905 as his own "extreme scholastic realism" (CP 8.208), as Peirce came to affirm the reality of generals. However, it is difficult to assess this "scholasticism". As John Boler argues, our own understandings of Peirce and of the scholastics are incomplete: "No one doubts Peirce's claim that he was significantly influenced by reading Scotus and other Scholastics, but there is some confusion about when, how much, and what Peirce ultimately made of it" (Boler 2004: 66).

\footnotetext{
${ }^{14}$ The reader interested in delving further into Peirce's evolving thought about reality may profit from contrasting Rosa Mayorga's (2007) and Paul Forster's (2011). Lane (2004) and Boler (2004), cited here, are good shorter introductions.
} 
What matters most for our purposes here is that, as with truth, Peirce adopts reality as a regulative ideal of inquiry - that is, he argues that inquiry itself is guided by the ideal of responsiveness to reality. We turn now to the ways in which reality plays a role in understanding Peirce's account of assertion: as it is implicated in assertions that meet the standard of truth, and as itself a standard guiding the practice of asserting.

\section{The true and the real}

Just as the practice of assertion is truth-involved, assertion is also a statement of, and commitment to, reality. To his comments about the first-person feel of assertion as the stable place reached at the end of inquiry, Peirce adds the functional claim that assertion "is intended to stimulate the hearer to make an answer" (CP 4.57). This means that assertion warrants a response because it is offered as a claim about how things are, such that any claim that fails to be about how things are simply lacks the right kind of intention - what Peirce elsewhere describes as the right kind of "effort" - to be an assertion at all. Assertion to another comes with a measure of assurance meant to attach not to the belief-set of the asserter, but to reality. As Peirce says, It is true that no language (so far as I know) has any particular form of speech to show that the real world is spoken of. But that is not necessary, since tones and looks are sufficient to show when the speaker is in earnest. These tones and looks act dynamically upon the listener, and cause him to attend to realities. (CP 2.337; R 786) An assertion is an assertion and not some other speech act in part because it is motivated by a kind of compulsion and the sincere effort to spread that compulsion, which we can now understand as something like "see here: this is how things stand". 
Terence Cuneo has made a similar point about the relation between intention and performance with regard to assertions as compared to sincere attitude-reports. Cuneo argues that expressing an attitude in a sentence is a different type of illocutionary act from asserting: "It is false that...when an agent performs the sentential act of sincerely uttering a...sentence, that agent does not thereby intend to assert a ... proposition, but intends to express an attitude" (Cuneo 2005: 46). At the heart of Cuneo's argument is the claim that illocutionary acts, as a form of doing, are what they are partly because of what we intend them to be. This echoes closely Peirce's note on the role of intention in the nature of assertion: "That which accounts for assertion seeming so different from other sorts of signification is its volitional character" (CP 2.436; R 595, emphasis in original). Peirce makes this clear when he says that "the pragmaticist grants ... that every assertion contains such a denotative or pointing-out function" (CP 5.429; 1905: 176). It is precisely this pointing out that distinguishes assertion as a speech act, where how things actually do stand is the arbiter of success or failure. Thus, in the case of assertion, the volition in question is what we might describe as a will toward the world - toward reality.

\section{Assertions as claims about how things really are}

When one asserts one always asserts a proposition, but assertions are not mere linguistic expressions of propositions. We have seen some reasons why this is the case already: since assertion requires an (at least potential or problematical) audience, one cannot assert in a vacuum. Also, as shown above, mere words cannot indicate whether one is referring to reality or, to use one of Peirce's favorite examples, a fictional world. Since truth is the norm of assertion, one cannot properly assert propositions that do not obtain in reality - or, at the minimum, propositions that did not arise as the result of an inquiry conducted under the regulative 
assumption of the hypothesis that there is some reality. The propriety of one's assertions are thus constrained by the way things really are, and the asserter is similarly constrained by the requirement that she not simply express a proposition, but that she also attempts to express a proposition that connects with reality.

However, the account sketched so far is still incomplete, since the conditions that one cannot assert in complete isolation and that the content of one's assertion ought to be true permit proper assertions of propositions that just so happen to be true for reasons that are beyond the understanding of the asserter, or that the asserter just could not care less about. Simply noting that proper assertions are governed by the way things really are gets us only part of the way to being able to distinguish "mere sayings" from assertions. It is not enough that the content of our assertions merely conform to reality; rather, proper assertion requires the taking of responsibility for the truth of what one asserts. It is to this final pragmatic entanglement that we turn next.

\section{Pragmatic Entanglements: Responsibility}

\section{Making oneself responsible to others}

An important aspect of Peirce's theory of assertion is that by asserting one undertakes a kind of commitment: by asserting proposition $p$ one thereby undertakes a commitment to defend the truth of $p$, or to be able to provide reasons for believing $p .{ }^{15}$ In Peirce's terms, asserting involves a "taking of responsibility": as is found in many places throughout his writings on assertion, Peirce held the view that "to assert [a] proposition is to make oneself responsible for it,

\footnotetext{
${ }^{15}$ One position in contemporary debates about assertion adopts a similar kind of view, what is aptly called a "commitment view" of assertion (see, for example, Searle (1969), Brandom (1983), Watson (2004), MacFarlane (2005)). While contemporary commitment views of assertion differ from Peirce's in a number of important ways (see Boyd (2016)), it is nevertheless surprising that, if a contemporary account of assertion should mention Peirce at all, it is almost always in passing.
} 
without any definite forfeit, it is true, but with a forfeit no smaller for being unnamed" (CP 5.543; R 596). Given what we have said about assertions already, it is not surprising why assertion involves the taking of responsibility: assertions are acts that have certain intended effects, namely the effect to try to get one's audience, or oneself, to accept the truth of the proposition asserted. Assertions, then, are not simply bare expressions of propositions in a linguistic form: they are acts with real effects, attempts to elicit change that require that one make oneself subject to the demands of truth.

Recall the passage from CP 5.546 (R 297), in which Peirce emphasized the fact that every genuine assertion must be "followed by very real effects." Utterances that do not have these effects, such as "I am perfectly delighted to see you", do not qualify as assertions. An utterance of "I am perfectly delighted to see you" is a verbal expression, and a verbal expression of a proposition. But whether it qualifies as an assertion turns on whether it involves the additional component of the taking of responsibility. As Peirce notes:

Neither the predicate, nor the subjects, nor both together, can make an assertion. The assertion represents a compulsion which experience, meaning the course of life, brings upon the deliverer to attach the predicate to the subjects as a sign of them taken in a particular way. This compulsion strikes him at a certain instant; and he remains under it forever after. (CP 3.435; R 518)

We can now appreciate the motivation for Peirce's insistence on the distinction between propositions and assertions thereof: propositions consist of a predicate and subject or subjects, but a mere proposition or the expression of a proposition does not by itself involve any compulsion to accept it. 
The same proposition, then, can be asserted or merely expressed, depending on the circumstances; the key difference between those circumstances again comes down to whether one takes responsibility for the truth of the proposition expressed. The aspect of taking responsibility is underscored by Peirce's emphasis on the potential punishments that one subjects oneself to when making an assertion. These punishments can vary: Peirce notes that if one perjures oneself in a court of law, one may "assent in judge and jury's minds [that] may effect in the minds of sheriff and posse a determination to an act of force to the detriment of some innocent man's liberty or property" (EP2: 312), while in a less stringent situation one might simply gain a bad reputation as someone who is untrustworthy - or, in Peirce's terms, be "set down as a trifler" (CP 1.274; R 426).

One may, of course, never actually receive any punishment if one asserts something false: given the quantity of false assertions made on a day-to-day basis we surely only chastise the speakers of a small proportion of them. The "problematical existence" of one's audience also constrains the circumstances under which one can be punished for a false assertion since, as we have seen, messages in bottles will still qualify as assertions. The potential for punishment, then, is reflective of the nature of taking responsibility for something in general: responsibility without the possibility of being held accountable is not real responsibility, and similarly asserting without the possibility of being held accountable for the truth of what one asserts is not real assertion. This is so even when we are our own audience.

\section{Making oneself responsible to oneself}

If judgments are assertions to oneself, then judgments must also involve an assumption of responsibility. But can I really stand in such a relation of responsibility to myself? Peirce clearly 
thinks that the answer is "yes." Consider "The Fixation of Belief": although part of what moves us to reject methods of belief fixation like tenacity and authority is the "social impulse", this is not the only thing motivating us toward inquiry. Recognizing belief as establishing habit for action reveals that we are responsible to ourselves in the sense of forming beliefs in a way that does not undercut our own purposes. On the way to making the normative claim that one should inquire, Peirce makes the descriptive claim that if we confront our own use of dodgy methods of belief fixation - if we come to see their lack of reliability for producing stable beliefs that will stand up to the pressures of future experience, that we confidently assert now and would continue to assert in the future without recalcitrant experience undermining us - we cannot use them. There is no going back to tenacity once one's faith in it has been undermined; by one's own lights, it is a failure. Once one confronts what a judgment privately made has to be able to do stand up not only to the criticism of one's peers if it were to be vocally asserted, but continue to inform one's plans and purposes - we see that we constrain ourselves by a truth-norm whether we are under social pressure or not. Nor can we get around this constraint by simply carving off private judgment from assertion. Since in our own experience of performing it, "the act of assertion is an act of a totally different nature from the act of apprehending the meaning of the proposition", one cannot choose to represent one's own reasoning processes as apprehensions or appreciations if they terminate in judgments (CP 5.30; R 301). What I do in judgment is lay claim to the truth: if I take this to be my own business, if I recognize the thought-process that terminates in judgment as one marked by cognitive aspiration - I am not merely having feelings, but trying to get something right - it seems that the responsibility I take on is the one inherent in 
being an inquirer. It is a requirement of intellectual integrity, to operate in good faith, not to accept half-measures. ${ }^{16}$

So Peirce thinks that we can be responsible for the truth in the privacy of our own judgments, but how could we observe - as he suggests we must - that this is so? The proof here, it seems, really has to be first-personal and phenomenological. If we are moved by the suggestion, as it appears in "Fixation", that we can't tolerate even in ourselves a method that doesn't aim at the truth, Peirce is off to a good start. More generally, if we experience our judgments as marked by cognitive aspiration - we think we are trying to get things right, rather than right-for-right-now - we place ourselves under a truth norm in the practice of silent assertion. This shows how deeply the weight of the responsibility that Peirce associates with assertion really goes.

Even in private judgment, we can see ourselves as having violated a law in asserting a falsehood. Critically, this doesn't have to be because we have internalized the social law under which we would be held responsible to the extent that we punish ourselves as our peers would although we can imagine that being the case. But Peirce suggests that it might be the "moral law" against which we measure our ill-made assertion:

For an act of assertion supposes that, a proposition being formulated, a person performs an act which renders him liable to the penalties of the social law (or, at any rate, those of the moral law) in case it should not be true, unless he has a definite and sufficient excuse; and an act of assent is an act of the mind by which one endeavors to impress the

\footnotetext{
${ }^{16}$ In her (1996) defense of the importance of truth for philosophy, Haack makes a similar point about integrity. While discussing Peirce's standards of inquiry, she remarks that "The genuine inquirer's love of truth ...is not like the love of a collector for the antique furniture or exotic stamps he collects, nor is like a religious person's love of God." Nor is the inquirer a mere "collector of true propositions", but rather "a person of intellectual integrity" (1996: 59) - that is to say, a person who holds herself responsible.
} 
meanings of the proposition upon his disposition, so that it shall govern his conduct. (CP $2.315 ; \mathrm{R} 478)$

It may take us awhile to come around to realizing that we have violated the moral law through an act that expresses some falsely made judgment - but the experience of regret, shame, or guilt upon the realization that one has made an error in judgment might all suggest that we do indeed give ourselves the consequences.

\section{Concluding Remarks}

In addition to the weight of our historical investigation, we conclude that the inseparability of assertion from truth, reality, and responsibility suggests that Peirce's view of assertion is central to his system. Our overarching purpose has been to defend the claim that Peirce has a view of assertion, a view which is in fact a central strand of his philosophical system. We have sought to assemble historical evidence of Peirce's consistent and coherent interest in assertion, to explore the philosophical contours of his view, and to showcase a plausible shift in interpretation on the basis of taking the centrality thesis seriously. By way of conclusion, we end on mere suggestion: we ought to be scientists, rather than rascals or triflers, in the ongoing project of assessing and applying Peirce's view of assertion. 


\section{Works Cited}

Anderson, Douglas (1995). Strands of System: The Philosophy of Charles Peirce. West Lafayette: Purdue University Press.

Atkins, Richard (2011). "This Proposition is Not True: C.S. Peirce and the Liar Paradox." Transactions of the Charles S. Peirce Society 47(4): 421-44.

Boler, John (2004). "Peirce and Medieval Thought". In Cheryl Misak (Ed.), The Cambridge Companion to Peirce, Cambridge: Cambridge University Press, 58-86.

Boyd, Kenneth. (2016). "Peirce on Assertion, Speech Acts, and Taking Responsibility." Transactions of the Charles S. Peirce Society 52(1): 21-46.

Brandom, Robert (1983). “Asserting.” Nous 17.4: 637-50.

Brock, Jarret E. (1981). “Peirce and Searle on Assertion.” In Ketner, Kenneth, Joseph M. Randsell, Carolyn Eisele, Max H. Fisch, and Charles S. Hardwick (eds.). Proceedings of the C.S. Peirce Bicentennial International Congress. Lubbock, TX: Texas Tech Press, 281-88.

Cuneo, Terence (2005). “Saying what we Mean: An Argument against Expressivism.” Oxford Studies in Metaethics, vol. 1. Oxford University Press, 2006: 35-71

Deledalle, Gérard (1990). Charles S. Peirce: An Intellectual Biography, translated by Susan Petrelli. John Benjamins Publishing Company. 
Forster, Paul (2011). Peirce and the Threat of Nominalism. Cambridge: Cambridge University Press.

Goudge, Thomas A. (1950). The Thought of C. S. Peirce. Toronto: University of Toronto press. Haack, Susan (1996). “Concern for Truth: What it Means, Why it Matters”. In Paul R. Gross, Norman Levitt, and Martin W. Lewis (Eds.), The Flight from Science and Reason, New York: New York Academy of Sciences, 57-63.

--- (1993). Evidence and Inquiry: Toward Reconstruction in Epistemology.Oxford: Blackwell Publishers.

Heney, Diana B. (2015). "Reality as Necessary Friction.” Journal of Philosophy 112(9): 504-14. Hilpinen, Risto (1982). “On C.S. Peirce's Theory of the Proposition: Peirce as a Precursor of Game-Theoretical Semantics.” The Monist 65.2: 182-88.

Hookway, Christopher (1985). Peirce. London: Routledge and Kegan Paul.

Houser, Nathan (1992). "Introduction.” The Essential Peirce, vol.1, Bloomington: Indiana University press: xix-xli.

Ladd-Franklin, Christine (1889). "On Some Characteristics of Symbolic Logic.” The American Journal of Psychology, 2.4: 543-567.

Lane, Robert (2004). “On Peirce's Early Realism.” Transactions of the Charles S. Peirce Society, Vol. XL, No.4.

MacFarlane, John (2005). “The Assessment Sensitivity of Knowledge Attributions.” In Gendler, Tamar and John Hawthorne (eds.). Oxford Studies in Epistemology.

Martens, Ekkehard. (1981). “C.S. Peirce on Speech Acts.” In Ketner, Kenneth, Joseph M. Randsell, Carolyn Eisele, Max H. Fisch, and Charles S. Hardwick (eds.). Proceedings of 
the C.S. Peirce Bicentennial International Congress. Lubbock, TX: Texas Tech Press, 28992.

Mayorga, Rosa Maria Perez-Teran (2007). From Realism to Realicism: The Metaphysics of Charles Sanders Peirce. Lexington Books.

Misak, Cheryl (2016). Cambridge Pragmatism: From Peirce and James to Ramsey and Wittgenstein. Oxford: Oxford University Press.

--- (2004 [1991]). Truth and the End of Inquiry, 2nd edition. Oxford: Oxford University Press. Peirce, C.S. (1905). “What Pragmatism Is.” The Monist 15.2: 161-183.

---. (1931-35, 1958). The Collected Papers of Charles Sanders Peirce. Vols. I-VI ed. Charles Hartshorne and Paul Weiss, Vols. VII-VIII ed. Arthur W. Burks. Cambridge: Harvard University Press.

---. (1991). The Essential Peirce: Vol. 2. Houser, Nathan and Christian Kloesel (eds.). Bloomington: Indiana University Press.

Price, Huw (2003). 'Truth as Convenient Friction'. The Journal of Philosophy, 100/4: 167 - 190. Ricketts, Thomas (1986). “Objectivity and Objecthood: Frege's Metaphysics of Judgment.” In Hintikka, J. and L. Haaparanta (eds.). Frege Synthesized. Springer.

Roberts, Don D. (2009 [1973]). The Existential Graphs of Charles S. Peirce (Approaches to Semiotics). De Gruyter Mouton.

Robin, Richard S. (1967). Annotated Catalogue of the Papers of Charles S. Peirce. Worcester: University of Massachusetts Press.

Searle, John (1969). Speech Acts: An Essay in the Philosophy of Language. Cambridge: Cambridge University Press.

Shin, Sun-Joo (2002). The Iconic Logic of Peirce's Graphs. Bradford Books. 
Short, T.L (2007). Peirce's Theory of Signs. Cambridge: Cambridge University Press.

Stjernfelt, Frederik. (2015). “Dicisigns: Peirce's semiotic doctrine of propositions.” Synthese 192: 1019-1054.

---. (2014). Natural Propositions: The Actuality of Peirce's Doctrine of Dicisigns. Docent Press:

Boston.

Watson, Gary (2004). “Asserting and Promising.” Philosophical Studies 117(1/2): 57-77

Wittgenstein, Ludwig (2009 [1953]). Philosophical Investigations, 4th edition, transl.

G.E.M. Anscombe, eds. P.M.S. Hacker and Joachim Schulte. Oxford: Blackwell. 